\title{
Detection of Long Storage and Sunflower Adulteration of Olive Oils Using an Ultra-violet (UV) Spectroscopy Method
}

\author{
M. Al-BACHIR ${ }^{a^{*}}$ AND Y. OTHMAN ${ }^{\mathrm{a}}$ \\ a RadiationTechnologyDep. AtomicEnergyCommission of Syria, P.O.Box: 6091, Damascus, Syria \\ ${ }^{*}$ Corresponding author \\ ascientific@aec.org.sy \\ TEL: 009-63-11-2132580
}

Received: 24 January 2018; Published online: 18 October 2019

\begin{abstract}
The purpose of the study was to evaluate the effects of Syrian Kaissy olive oil (SKOO) adulteration and long storage periods on the basic quality indices namely, peroxide value (PV), acid value (AV), and absorbance of $\mathrm{UV}\left(\mathrm{K}_{232}, \mathrm{~K}_{270}, \Delta \mathrm{K}\right.$ and $\mathrm{R}\left(\mathrm{K}_{232} / \mathrm{K}_{270}\right)$ values).

This study revealed that the quality indexes, including $\mathrm{AV}, \mathrm{PV}, \mathrm{K}_{232}, \mathrm{~K}_{270}$ and $\Delta \mathrm{K}$ values, of all SKOO specimens increased with increasing storage time. It was revealed that the $\mathrm{K}_{232}, \mathrm{~K}_{270}$ and $\Delta \mathrm{K}$ values of SKOO specimens stored for 1 and 2 years remained under the limits, established by International Olive Council (IOC), of 2.5, 0.22 and 0.01 units, respectively. While in some cases, the $\mathrm{K}_{232}, \mathrm{~K}_{270}$ and $\Delta \mathrm{K}$ values exceeded their respective limits after 8,9 and 10 years of storage. The index of $\mathrm{R}$ $\left(\mathrm{K}_{232} / \mathrm{K}_{270}\right)$ decreased with time of storage.
\end{abstract}

Keywords: Adulteration; Olive oil; Oxidation; Storage period; Syria; UV absorbance

\section{Introduction}

Olive oil has been regarded as "liquid gold" from antiquity. Among the several types of edible oils, extra virgin olive oil (EVOO) is considered as the best organoleptically, which is obtained only by mechanical or physical methods, without involving any thermal alteration or treatment. It is an important oil that has a high nutrition value (Gonzalez, Aparicio-Ruiz, \& Aparicio, 2008). Olive oil contains unsaturated fats in the form of poly unsaturated fatty acids and mono unsaturated fatty acids which are good for health (Al-Bachir \& Sahloul, 2017; Al-Bachir \& Koudsi, 2016).

Due to its higher price, virgin olive oil is often adulterated with cheaper vegetable oils (Nikolova, Eftimov, Antova, \& Brabant, 2013). There is a need to develop reliable analytical methods to ensure compliance of olive oil quality with labeling, and to determine the genuineness of the product by detection of eventual defects during adulteration, processing and storage (Abbadi et al., 2014).

In the literature, different methods used in the detection of olive oil adulteration are reported (Frankel, 2010). They include the iodine value, saponification value, oxidation value as well as refractive index, density, viscosity, volatile compounds, and olive oil antioxidants measurements (Amereih, Barghouthi, \& Marowan, 2014; Fernandes, Umebara, Lenzi, \& Teixeira Silva, 2013). To determine the type of adulterant, chemical methods such as gas chromatography or high performance liquid chromatography are used (Inthiram, Mirhosseini, Tan, Mohamad, \& Lai, 2015). Ultraviolet (UV) spectroscopy can provide information on the degree of oxidation of the olive oil (Nikolova, Eftimov, Perifanova, \& Brabant, 2012). More specifically, the quality of olive oil is 
analyzed based on the absorption band between 200 and $300 \mathrm{~nm}$, which can be used to evaluate the presence of refined oils in virgin olive oil (Aued-Pimentel, Alves da Silva, Takemoto, \& Cano, 2013).

Current European Union regulation (European Communities, 2013) and the International Olive Council International Olive Council (2015) require olive oils to be graded based on sensory assessment and three fundamental chemical parameters: free acidity, peroxide value and UV absorbance. By comparing oils' scores with threshold values, these are categorised as extra virgin olive oil (EVOO), virgin olive oil (VOO) and other low-quality ordinary olive oil (OOO).

This study was conducted to determine if storage period could induce measurement changes in the Ultra-violet UV spectrophotometric absorbance values at $232 \mathrm{~nm}$ and $270 \mathrm{~nm}$ (K232, $\mathrm{K} 270, \Delta \mathrm{K}$ and $\mathrm{R}(\mathrm{K} 232 / \mathrm{K} 270)$ values) of Syrian Kaissy olive oil (SKOO). Samples were stored at room temperature conditions and the results obtained under different storage periods $(1,2,8,9$ and 10 years) were compared.

\section{Materials and Methods}

\subsection{Chemical and reagents}

Olive oil, from olives harvested in the 2007, 2008, 2009, 2015 and 2016 seasons, was obtained from olive fruits of Kaissy cultivar grown in orchards located at the Deer Al Hajar research station, southeast Damascus, Syria $\left(33^{\circ} 21^{\prime} \mathrm{N}, 36^{\circ} 28^{\prime}\right.$ E) at $617 \mathrm{~m}$ above sea level, under conventional agriculture practices. The oil was extracted at the shortest time possible using mechanical and physical processes (Blatchly, Delen, \& O'Hara, 2014). Olive fruits were crushed with a hammer crusher and slowly mixed for about $30 \mathrm{~min}$ at $27^{\circ} \mathrm{C}$. Then, the mixed paste was centrifuged at $3000 \mathrm{rpm}$ for $3 \mathrm{~min}$ without addition of water to extract the oil. Finally, the oils were decanted and immediately transferred into dark glass bottles and stored at room temperature. Olive oils were extracted and stored at our lab. Chemical and physical analyses were performed on SKOO samples in 2017 (after 1, 2, 8, 9 and 10 years of storage).
Adulteration was carried out in triplicate in 2017 in our lab by mixing olive oil samples produced in 2016 with sunflower oil (SO), purchased from a local supermarket in 2017, at different blending ratios $(0: 100,2: 98$. 4:96, 6:98, 8:92, 10:90, $20: 80,30: 70,40: 60,50: 50,60: 40,70: 30,80: 20$, 90:10, 100:0 (v/v)). Physical analyses were performed on SKOO, SO and mixed oil samples in 2017 (after 1 year of storage).

\subsection{Chemical and physical analysis of oils}

Acid value (AV, oleic acid \%) and peroxide value $\left(\mathrm{PV}\right.$, meq $\left.\mathrm{O}_{2} \mathrm{~kg}^{-1}\right)$ were determined according to standard methods (Association of Official Analytical Chemists, 2010). Absorbance of UV was used to detect abnormal oxidation compounds in olive, sunflower and mixed oil samples according to norms established by IOC (Ait Taleb, Boutoial, Kzaiber, \& Oussama, 2016). $\mathrm{K}_{232}$ and $\mathrm{K}_{270}$ were calculated from absorption at 232 and $270 \mathrm{~nm}$, respectively. $\Delta \mathrm{K}$ was calculated from 266, 270 and $274 \mathrm{~nm}$ absorptions using the following equation:

$$
\Delta K=K_{270}-\left(K_{266}-K_{274}\right) \cdot \frac{1}{2}
$$

The $R$ value was calculated as $K_{232}$ divided by $\mathrm{K}_{270}$. A T70 UV-Visible spectrophotometer (PG Instruments Limited, England) was used with a $1 \%$ solution of oil in cyclohexane and a path length of $1 \mathrm{~cm}$. $0.25 \mathrm{~g}$ of oil was dissolved in $25 \mathrm{~mL}$ of cyclohexane and the absorbance of the solution was then measured at the specified wavelengths with reference to pure solvent. Specific extinction is calculated from the spectrophotometer reading (UVWin5.0 program) using a quartz cell with $1 \mathrm{~cm}$ optical path.

\section{$2.3 \quad$ Statistical analysis}

The five storage periods and 15 levels of adulterations were distributed in a completely randomized design, with three replicates. Data were subjected to an analysis of variance test (ANOVA) using the SUPERANOVA computer package (Abacus Concepts Inc., Berkeley, CA, 
36|Al-Bachir and Othman

USA; 1998). The $P$ value of less than 0.05 was considered for statistical significance.

\section{Results and Discussions}

\subsection{Basic quality parameters of investigated virgin olive oils}

Acid value (AV): Table 1 shows the averaged values obtained for AV indices of SKOO and their respective standard deviations during the whole storage time (1, 2, 8, 9 and 10 years). It is worth mentioning that during storage at room temperature, the AV of stored SKOO increased with increasing time of storage. Data presented in Table 1 shows that the AV of stored SKOO for one year $(2.71 \%), 2$ years $(2.95 \%)$, and 8 years $(2.17 \%)$ were below the maximum levels. The AV of SKOO stored for 9 years $(4.16 \%)$ and 10 years $(4.39 \%)$ exceeded the maximum levels established by the international regulations, which are the maximum levels established by the IOC for an oil to be considered as an ordinary virgin olive oil. According to the standard of the International Olive Council International Olive Council (2015), there should be a maximum of $1.0,2.0$ and $3.3 \%$ acidity in extra virgin olive oil (EVOO), virgin olive oil (VOO) and ordinary olive oils (OOO), respectively. The free fatty acids, measured as acidity (\% oleic acid $(\mathrm{C} 18: 1))$, is a very important quality and classification index for olive oils. It is a measurement of the hydrolytic breakdown of fatty acid chains from triglycerides into diglycerides and monoglycerides, liberating free fatty acids (Tanoitu, Elamrani, Serghini-Caid, \& Tahani, 2011).

Peroxide value (PV): According to the IOC standard, the maximum allowable PV for EVOO, $\mathrm{VOO}$ and $\mathrm{OOO}$ is 20 meq $\mathrm{O}_{2} \mathrm{~kg}^{-1}$ oil (International Olive Council, 2015). It is worth mentioning that $\mathrm{PV}$ in SKOO samples stored for 1 year were less than the value of 20 meq $\mathrm{O}_{2} \mathrm{~kg}^{-1}$ (16.68 meq $\mathrm{O}_{2} \mathrm{~kg}^{-1}$ ), while the PV in SKOO samples stored for 2 and 8 years were around the value of 20 meq $\mathrm{O}_{2} \mathrm{~kg}^{-1}$ (20.78 and 20.74 meq $\mathrm{O}_{2}$ $\mathrm{kg}^{-1}$, respectively) and the PV in SKOO samples stored for 9 and 10 years exceeded the value of 20 meq $\mathrm{O}_{2} \mathrm{~kg}^{-1}$ (26.16 and 27.58 meq $\mathrm{O}_{2} \mathrm{~kg}^{-1}$, respectively) (Table 1 ). During storage, an in- crease in PV was observed as a consequence of the action of both diluted and headspace oxygen in the bottle that induce a rapid deterioration. Then the PV was progressively reduced because of the degradation into secondary products. This could be explained as the evolution of autoxidation which depends on the light, temperature and vacuum activity (Vekiari, Papadopoullou, \& Kiritsakis, 2007). These results are in line with those reported by Papuc, Nicorescu, and Durdun (2009) where PV is taken as a measure of primary oxidation compounds produced in the oxidation of oil samples. Oxidation of oil generates a multitude of compounds, such as acids with short chain molecules formed by the oxidation of aldehydes. The quality of olive oil reduced during storage due to oxidation that leads to rancidity (Vacca, Del Caro, Poiana, \& Piga, 2006). Variation during olive oil storage and transportation leads to lipid oxidation, which is due to natural or climatic conditions (Silva, Rodrigues Anjos, Cavalcanti, \& dos Santos Celeghini, 2015). Similar results have been reported for extra-virgin olive oil which was stored for 6 years, where free acidity exceeded the limit recommended for EVOO by IOC, whereas, the stability against oxidation persisted for a longer period of time due to the high concentration of oleuropein derivatives (Baiano, Terracone, Viggiani, \& Alessandro Del Nobile, 2014).

Lipids containing polyunsaturated fatty acids and their esters are exposed to autoxidation by molecular oxygen. Autoxidation of lipids has been recognized as a major deterioration process affecting the quality properties of foods, which limits shelf-life (Ait Taleb et al., 2016). The importance of virgin olive oil is related to its high levels of monounsaturated fatty acids (mainly oleic acid (C18:1)), and the low levels of polyunsaturated fatty acids (linoleic acid (C18:2) and linolenic acid (C18:3)) (Al-Bachir \& Sahloul, 2017; Al-Bachir \& Koudsi, 2016).

\subsection{Influence of storage period on UV spectrophotometric absorbance of SKOO}

The mean \pm standard deviation values of $\mathrm{K}_{232}$, $\mathrm{K}_{270}, \Delta \mathrm{K}$ and $\mathrm{R}\left(\mathrm{K}_{232} / \mathrm{K}_{270}\right)$ of SKOO samples 
Detection of olive oil adulteration $\mid 37$

Table 1: Effect of production year on acid value and peroxide value of Syrian Kaissy olive oil

\begin{tabular}{cccc}
\hline $\begin{array}{c}\text { Storage period } \\
\text { (years) }\end{array}$ & $\begin{array}{c}\text { Production } \\
\text { year }\end{array}$ & $\begin{array}{c}\text { Acid value } \\
\text { (oleic acid \%) }\end{array}$ & $\begin{array}{c}\text { Peroxide value } \\
\left(\text { meq O }_{2} \mathbf{k g}^{-1} \text { oil }\right)\end{array}$ \\
\hline 1 & 2016 & $2.71 \pm 0.01$ & $16.68 \pm 1.30$ \\
2 & 2015 & $2.95 \pm 0.09$ & $20.78 \pm 0.54$ \\
8 & 2009 & $2.17 \pm 0.29$ & $20.74 \pm 2.15$ \\
9 & 2008 & $4.16 \pm 0.87$ & $26.16 \pm 1.01$ \\
10 & 2007 & $4.39 \pm 2.64$ & $27.58 \pm 7.05$ \\
\hline P-Value & & $\mathbf{0 . 0 0 7 0}$ & $\mathbf{0 . 0 0 0 4}$ \\
\hline
\end{tabular}

Table 2: Specific extinction coefficient UV at 232, 266, 268, 270 and $274 \mathrm{~nm}$ of Syrian Kaissy olive oil

\begin{tabular}{cccccc}
\hline $\begin{array}{c}\text { Storage period } \\
\text { (years) }\end{array}$ & $\begin{array}{c}\text { Production } \\
\text { year }\end{array}$ & $\mathbf{K}_{232}$ & $\mathbf{K}_{270}$ & $\Delta \mathbf{K}$ & $\begin{array}{c}\mathbf{R} \\
\left(\mathbf{K}_{232} / K 270\right)\end{array}$ \\
\hline 1 & 2016 & $2.161 \pm 0.002$ & $0.174 \pm 0.001$ & $0.002 \pm 0.000$ & $12.41 \pm 0.062$ \\
2 & 2015 & $2.128 \pm 0.001$ & $0.147 \pm 0.000$ & $0.002 \pm 0.000$ & $14.48 \pm 0.010$ \\
8 & 2009 & $2.290 \pm 0.280$ & $0.352 \pm 0.120$ & $0.010 \pm 0.000$ & $6.51 \pm 1.610$ \\
9 & 2008 & $2.367 \pm 0.030$ & $0.469 \pm 0.004$ & $0.020 \pm 0.000$ & $5.05 \pm 0.036$ \\
10 & 2007 & $2.574 \pm 0.030$ & $0.597 \pm 0.150$ & $0.030 \pm 0.000$ & $4.31 \pm 0.060$ \\
\hline P-Value & & $*$ & $*$ & $*$ & $*$
\end{tabular}

*: Significant at $\mathrm{p}<0.05$

tested and their variation with time of storage are given in Table 2. The maximum values for $\mathrm{K}_{232}, \mathrm{~K}_{270}$ and $\Delta \mathrm{K}$ are, respectively, 2.5, 0.22 and 0.01 for extra virgin olive oils, 2.6, 0.25 and 0.01 for virgin olive oils and 2.6, 0.30 and 0.01 for ordinary virgin olive oils (International Olive Council, 2015). After 1 and 2 years of storage, SKOO samples presented $K_{232}, K_{270}$ and $\Delta K$ values less than the maximum limits established for the extra virgin category. However, a sample of SKOO presented a $\mathrm{K}_{232}$ value of 2.574 after 10 years of storage, $K_{270}$ value of 0.352 after 8 years of storage and $\Delta \mathrm{K}$ value of 0.02 after 9 years of storage, and these values are higher than the maximum limit established for the EVOO category. Finally, the $\mathrm{R}$ value $\left(\mathrm{K}_{232} / \mathrm{K}_{270}\right)$ of SKOO decreased with time of storage (Table 2). $\mathrm{R}$ values were $12.41,14.48,6.51,5.05$ and 4.31 for SKOO samples stored for 1, 2, 8, 9 and 10 years respectively. Similar results for the effect of storage time on the quality parameters of olive oil have been reported by several authors. Ab- badi et al. (2014) reported that the extinction coefficients, $K_{232}$ and $K_{270}$, of olive oil stored at elevated temperature increased continuously and significantly with extending time of storage. In recent years, several authors have reported results for different olive oil varieties under storage conditions lasting 12-18 months. Low temperatures preserve the properties of a fresh olive oil better than room temperatures (Brkić Bubola, Koprivnjak, Sladonja, \& Belobrajić, 2014; Mulinacci et al., 2013). The extinction coefficients, $\mathrm{K}_{232}$ and $\mathrm{K}_{270}$, of virgin olive oil depended on the year of production (2001, 2002 and 2003) (Ninfali et al., 2008). Determination of the absorption coefficients in the ultra-violet region $(232 \mathrm{~nm}$ and $270 \mathrm{~nm}$ ) reflects the stage of oxidation for olive oil during storage (Kiritsakis, Kanavouras, \& Kiritsakis, 2002). The $K_{232}$ value reportedly is correlated with peroxide value, not only at time zero but also during storage. Higher readings of $\mathrm{K}_{232}$ in these samples may indicate improper storage of the oils (Ogutcu, Mendes, \& Yilmaz, 2008). 
$\mathrm{K}_{232}, \mathrm{~K}_{270}$ and $\Delta \mathrm{K}$ parameters indicated a substantial increase of primary oxidation, measured by the peroxide value (formation of hydroperoxides) and $\mathrm{K}_{232}$ (formation of conjugated dienes), and of secondary oxidation, as shown by $\mathrm{K}_{270}$ and $\Delta \mathrm{K}$ (formation on conjugated trienes) starting from the seventh year of storage (Baiano et al., 2014). Under room temperature storage, the increase in oxidation, confirmed by the increase in extinction coefficients, occurred in both due to the increase in the number of compounds resulting from peroxide degradation (Vekiari et al., 2007). Silva et al. (2015) reported that $K_{232}$ and $\mathrm{K}_{270}$ values varied in relation to storage time.

Because of the significant variation of $\mathrm{K}_{232}$ and $\mathrm{K}_{270}$ values during olive oil storage, in response to oil oxidation, these parameters may be of major quality control importance for stored extra virgin olive oil in terms of determining the time at which they will lose their extra category (Abbadi et al., 2014).

\subsection{Influence of storage period and adulteration ratios on UV spectrophotometric absorbance of SKOO}

Figure 1 shows the changes in the $\mathrm{K}_{232}$ specific extinction coefficient at different storage times and adulteration ratios. It was found that both storage time and adulteration ratio significantly affected the $\mathrm{K}_{232}$ specific extinction coefficient $(\mathrm{P}<0.05)$. The initial $\mathrm{K}_{232}$ specific extinction coefficient value was less than 2.5 , the maximum value established by the national and international regulations for EVOO (International Olive Council, 2015). An increase in storage time and adulteration ratio increased the $K_{232}$ specific extinction coefficient significantly $(\mathrm{P}<0.05)$, and reached 2.574 after 10 years of storage for SKOO and 4.902 in a mixture of SKOO and $\mathrm{SO}$ at a ratio of 9:1 (SO:SKOO). This indicates that adulteration of SKOO with SO has a greater effect on the formation of conjugated dienes in SKOO than the long storage time.

The changes in $\mathrm{K}_{270}$ specific extinction coefficient at different storage time and adulteration ratio are illustrated in Figure 2. The results of analysis of variance (ANOVA) indicate that both the storage time and adulteration ratio significantly affected the $\mathrm{K}_{270}$ specific extinction coefficient $(\mathrm{P}<0.05)$. The initial $\mathrm{K}_{270}$ specific extinction coefficient value was less than 0.22 , the maximum value established by the national and international regulations for EVOO (International Olive Council, 2015). An increase in storage time and adulteration ratio increased the $\mathrm{K}_{270}$ specific extinction coefficient significantly $(\mathrm{P}<0.05)$, and reached 0.597 after 10 years of storage for SKOO and 2.761 in a mixture of $\mathrm{SKOO}$ and $\mathrm{SO}$ at a ratio of 9:1 (SO:SKOO). This indicates that adulteration of SKOO with $\mathrm{SO}$ has a greater effect on formation of conjugated trienes in SKOO than the long storage time.

Figure 3 shows the changes in $\Delta \mathrm{K}$ value of SKOO at different storage time and adulteration ratio. It was found that both the storage time and adulteration ratio significantly affected the $\Delta \mathrm{K}$ value $(\mathrm{P}<0.05)$. The initial $\Delta \mathrm{K}$ value was less than the 0.01 , the maximum value established by the national and international regulations for EVOO (International Olive Council, 2015). An increase in storage time and adulteration ratio increased the $\Delta \mathrm{K}$ value significantly $(P<0.05)$, and reached 0.03 after 10 years of storage for SKOO and 0.37 in a mixture of SKOO and SO at a ratio of 9:1 (SO:SKOO). This indicates that adulteration of SKOO with $\mathrm{SO}$ has a greater effect on the $\Delta \mathrm{K}$ value in SKOO than the long storage time.

The changes in $\mathrm{R}$ value $\left(\mathrm{K}_{232} / \mathrm{K}_{270}\right)$ at different storage time and adulteration ratio are illustrated in Figure 4. The results of analysis of variance (ANOVA) indicate that both storage time and adulteration ratio significantly affected the $R$ value $(P<0.05)$. The initial $R$ value of SKOO was around 12.42. An increase in storage time and adulteration ratio decreased the $\mathrm{R}$ value significantly $(\mathrm{P}<0.05)$, and reached 4.31 after 10 years of storage for SKOO and 1.78 in a mixture of SKOO and SO at a ratio of 9:1 (SO:SKOO). This indicates that adulteration of SKOO with $\mathrm{SO}$ has a greater effect on $\mathrm{R}$ value in SKOO than the long storage time.

UV spectrophotometric measurements are widely used in both olive oil authentication and quality assessments (Escudero, Ramos, La Rubia García, \& Pacheco, 2016). European Commission Regulation No 2568/91 defines

IJFS | October 2019 | Volume 8 | pages 34-42 
specific extinction coefficients at $232 \mathrm{~nm}$ and 270 $\mathrm{nm}$ as the parameters related to the oxidation state of olive oil (Jenisová, Braniša, Jomová, \& Porubská, 2014). Absorbance at specific wavelengths in UV is a more delicate indicator of oxidation, and is related to the presence of a conjugate diene and triene system. Ultraviolet absorbance at 232 and $270 \mathrm{~nm}$, respectively are conventionally indicated by $\mathrm{K}_{232}$ (an indication of conjugated polyunsaturated fatty acids in olive oil), and $K_{270}$ (an indication of carbonylic compounds: aldehydes and ketones) (Amereih et al., 2014; Noorali, Barzegar, \& Sahari, 2014). When linoleic acid is oxidized to form hydroperoxides, a shift of the double bonds occurs producing a conjugated diene that can be measured by UV absorbance at $232 \mathrm{~nm}$. The increase of absorptivity at $232 \mathrm{~nm}$ was progressive for all oils, especially for oils rich in linoleic acid (sunflower, maize germs and soy oil) (Papuc et al., 2009). The oxidation stability of oil is a function of the fatty acid composition, and decreases with higher contents of linoleic and linolenic acids (Souza, De Almeida, Batista, De, \& Rios, 2011). However, SKOO contains more oleic acid and less linoleic and linolenic acids than other vegetable and seed oils. Oleic acid is a monounsaturated fatty acid, whereas linoleic and linolenic acids are polyunsaturated fatty acids. The main fatty acids in SKOO are: palmitic acid (C16:0) (13.11-15.89\%); stearic (C18:0) (2.19-3.83\%); oleic acid (C18:1) (68.94\%), (68.15-72.64\%); linoleic acid (C18:2) (7.65-12.51\%); Linolenic acid (C18:3) (0.411.09\%.) (Al-Bachir \& Sahloul, 2017; Al-Bachir \& Koudsi, 2016).

\section{Conclusion}

This study evaluated the changes in oxidative stability of SKOO during long storage time and adulteration ratios with SO. The results of analysis of variance (ANOVA) indicated that both storage time and adulteration ratio significantly affected the $\mathrm{K}_{232}, \mathrm{~K}_{270}, \Delta \mathrm{K}$ and $\mathrm{R}$ $\left(\mathrm{K}_{232} / \mathrm{K}_{270}\right)$ values $(\mathrm{P}<0.05)$. The adulteration of SKOO with sunflower oil had a greater effect on $\mathrm{K}_{232}, \mathrm{~K}_{270}, \Delta \mathrm{K}$ and $\mathrm{R}\left(\mathrm{K}_{232} / \mathrm{K}_{270}\right)$ values in SKOO than a long storage time. The

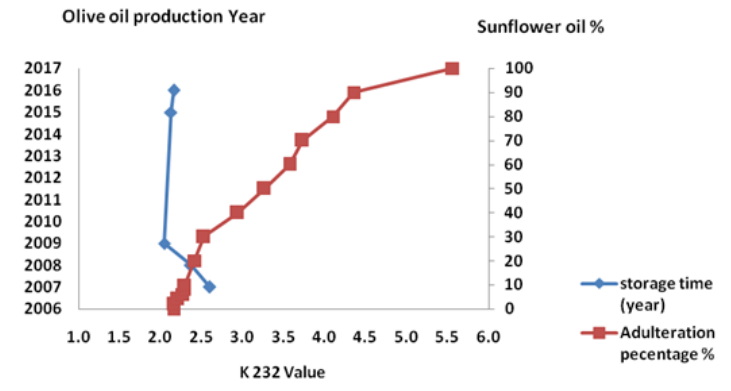

Figure 1: Effect of production year and adulteration percentage on the increase in $\mathrm{K}_{232}$ value of Syrian Kaissy olive oil

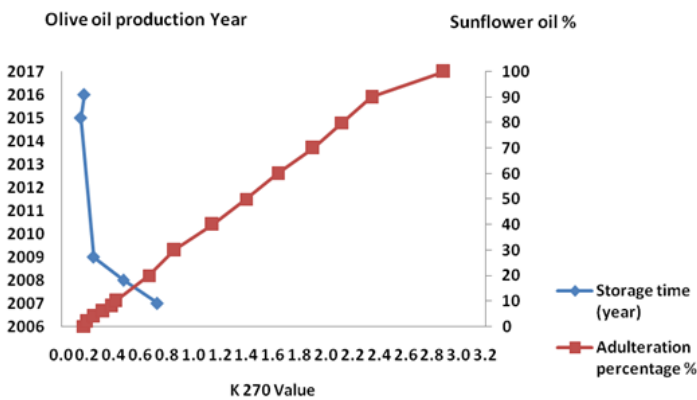

Figure 2: Effect of production year and adulteration percentage on the increase in $K_{270}$ value of Syrian Kaissy olive oil

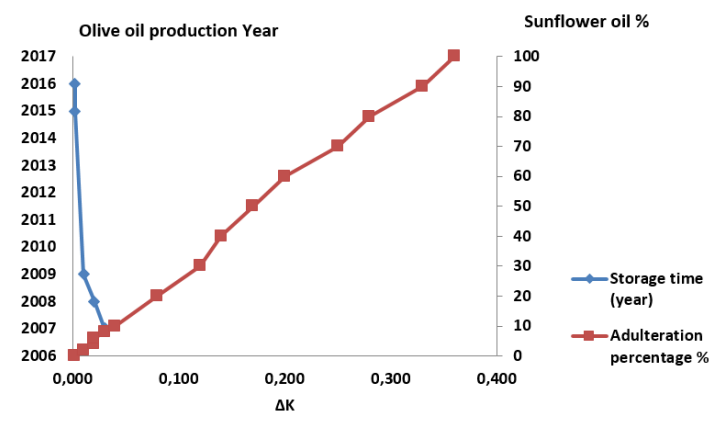

Figure 3: Effect of production year and adulteration percentage on the increase in delta- $K$ value of Syrian Kaissy olive oil 


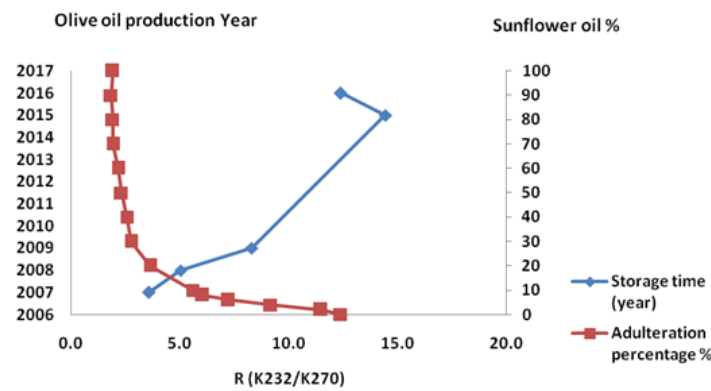

Figure 4: Effect of production year and adulteration percentage on the increase in $R$ value $\left(\mathrm{K}_{232} / \mathrm{K}_{270}\right)$ of Syrian Kaissy olive oil

$\mathrm{K}_{232}$ specific extinction coefficient of SKOO exceeded the maximum allowable limit of national and international regulations after 10 years of storage (2.574) and above an adulterant ratio of 1:2 (SO:SKOO)(2.526). The $\mathrm{K}_{270}$ specific extinction coefficient of SKOO exceeded the maximum allowable limit after 8 years of storage (0.352) and above an adulterant ratio of $1: 24$ (SO:SKOO)(0.24). The $\Delta \mathrm{K}$ value of SKOO exceeded the maximum allowable limit after 9 years of storage (0.02) and above an adulterant ratio of 1:24 (SO:SKOO)(0.02).

\section{Acknowledgements}

The authors wish to express deep appreciation to the Director General of the Atomic Energy Commission of Syria (AECS) and the staff of the division of food irradiation.

\section{References}

Abbadi, J., Afaneh, I., Ayyad, Z., Al-Rimawi, F., Sultan, W., \& Kanaan, K. (2014). Evaluation of the effect of packaging materials and storage temperatures on quality degradation of extra virgin olive oil from olives grown in palestine. American Journal of Food Science and Technology, Science and Education Publishing, 162-174. doi:10.12691/ajfst-2-5-5
Ait Taleb, S., Boutoial, K., Kzaiber, F., \& Oussama, A. (2016). Effect of aromatization by aromatic plants on the physicochemical, sensorial and oxidative stability of moroccan virgin olive oil. Int. J. Chem. Mater. Environ. Res. (ISSN 2410-5945), 3, 73-77.

Amereih, S., Barghouthi, Z., \& Marowan, O. (2014). Detection and quantification of adulteration in olive oil using a uv- spectrophotometric method. Palestine Technical University Research Journal, 20, 2, 1419.

Association of Official Analytical Chemists. (2010). Official methods of analysis. 15th ed. Association of Official Analytical Chemists," Washington, D.C.

Aued-Pimentel, S., Alves da Silva, S., Takemoto, E., \& Cano, C. (2013). Stigmastadiene and specific extitntion $(270 \mathrm{~nm})$ to evaluate the presence of refined oils in virgin olive oil commercialized in brazil. Food Sci. Technol. doi:10 . 1590 / S0101 20612013005000067

Al-Bachir, M., \& Sahloul, H. (2017). Fatty acid profile of olive oil extracted from irradiated and non-irradiated olive fruits. International Journal of Food Properties, 20(11), 2550-2558. Retrieved from 10 . 1080/10942912.2016.1243557

Al-Bachir, M., \& Koudsi, A. (2016). Fatty acid composition of oil obtained from irradiated and non-irradiated whole fruit and fruit flesh of olives (Olea europaea 1.). Annals of the University Dunarea de Jos of Galati Fascicle V - Food Technology, 40(1), 7889.

Baiano, A., Terracone, C., Viggiani, I., \& Alessandro Del Nobile, M. (2014). Changes produced in extra-virgin olive oils from cv. coratina during a prolonged storage treatment. Czech Journal of Food Sciences, 32, 1-9. doi:10.17221/79/2013-CJFS

Blatchly, R., Delen, Z., \& O'Hara, P. (2014). Making sense of olive oil: Simple experiments to connect sensory observations with the underlying chemistry. Journal of chemical education, 91, 1623-1630. doi:10.1021/ ed300557r

Brkić Bubola, K., Koprivnjak, O., Sladonja, B., \& Belobrajić, I. (2014). Influence of stor-

\begin{tabular}{l|l|l|l} 
IJFS | October 2019 & Volume 8 & pages 34-42
\end{tabular} 
Detection of olive oil adulteration $\mid 41$

age temperature on quality parameters, phenols and volatile compounds of croatian virgin olive oils. Grasas y Aceites, 65. doi:10.3989/gya.0222141

Escudero, A., Ramos, N., La Rubia García, M. D., \& Pacheco, R. (2016). Influence of extreme storage conditions on extra virgin olive oil parameters: Traceability study. Journal of Analytical Methods in Chemistry, 2016, 1-10. doi:10 . 1155 / 2016/ 7506807

European Communities. (2013). Commission implementing regulation no 1348/2013. Official Journal of European Union (Regulation No 134812-13 L338/31, 16 December. Retrieved from http://www.beuth.de/en/ regulation\%20euv-1348-20131200370127

Fernandes, J. K., Umebara, T., Lenzi, M., \& Teixeira Silva, E. (2013). Image analysis for composition monitoring. commercial blends of olive and soybean oil. Acta Scientiarum. Technology, 35. doi:10.4025/ actascitechnol.v35i2.15216

Frankel, E. N. (2010). Chemistry of extra virgin olive oil: Adulteration, oxidative stability, and antioxidants. Journal of agricultural and food chemistry, 58, 5991-6006. doi:10.1021/jf1007677

Gonzalez, D., Aparicio-Ruiz, R., \& Aparicio, R. (2008). Virgin olive oil - chemical implications on quality and health. European Journal of Lipid Science and Technology, 110, 602-607. doi:10.1002/ejlt.200700262

International Olive Council. (2015). Trade standard applying to olive oils and olive pomace oil. coi/t.15/nc no 3/rev.9.

Inthiram, A. K., Mirhosseini, H., Tan, C., Mohamad, R., \& Lai, O. M. (2015). Application of multivariate analysis for detection of crude palm oil adulteration through fatty acid composition and triacylglycerol profile. Pertanika Journal of Tropical Agricultural Science, 38, 389-398.

Jenisová, Z., Braniša, J., Jomová, K., \& Porubská, M. (2014). Variations of some nutrition values of olive oil by household using. Journal of Microbiology, Biotechnology and Food Sciences, 3(Special Issue 3), 221-224.
Kiritsakis, A., Kanavouras, A., \& Kiritsakis, K. (2002). Chemical analysis, quality control and packaging issues of olive oil. European Journal of Lipid Science and Technology, 104, 628-638. doi:10.1002/chin.200307280

Mulinacci, N., Ieri, F., Ignesti, G., Romani, A., Michelozzi, M., Creti, D., ... Calamai, L. (2013). The freezing process helps to preserve the quality of extra virgin olive oil over time: A case study up to 18months. Food Research International, 54. 2008-2015. doi:10.1016/j.foodres.2013.03. 052

Nikolova, K., Eftimov, T., Antova, G., \& Brabant, D. (2013). Detection of corn and sunflower oil adulterations of olive oils using fluorescence spectroscopy. Trakya University Journal of Natural Sciences, 14 (1), 1530.

Nikolova, K., Eftimov, T., Perifanova, M., \& Brabant, D. (2012). Quick fluorescence method for the distinguishing of vegetable oils. Journal of Food Science and Engineering, 2, 674-684. doi:10.17265/2159-5828/2012. 12.002

Ninfali, P., Bacchiocca, M., Biagiotti, E., Esposto, S., Servili, M., Rosati, A., \& Montedoro, G. (2008). A 3-year study on quality, nutritional and organoleptic evaluation of organic and conventional extra-virgin olive oils. Journal of the American Oil Chemists Society, 85(2), 151-158. doi:10. 1007/s11746-007-1171-0

Noorali, M., Barzegar, M., \& Sahari, M. A. (2014). Sterol and fatty acid compositions of olive oil as an indicator of cultivar and growing area. Journal of the American Oil Chemists Society, 91(9), 15711581. doi:10.1007/s11746-014-2497-z

Ogutcu, M., Mendes, M., \& Yilmaz, E. (2008). Sensorial and physico-chemical characterization of virgin olive oils produced in canakkale. Journal of the American Oil Chemists Society, 85(5), 441-456. doi:10. 1007/s11746-008-1220-3

Papuc, C., Nicorescu, V., \& Durdun, C. (2009). Evaluation of antioxidant activity of some plant extracts upon vegetal oils under thermal oxidation. American-Eurasian Journal of Sustainable Agriculture, 3, 157-164. 
Silva, S. F., Rodrigues Anjos, C. A., Cavalcanti, R. N., \& dos Santos Celeghini, R. M. (2015). Evaluation of extra virgin olive oil stability by artificial neural network. Food Chemistry, 179, 35-43. doi:10.1016/ j . foodchem.2015.01.100

Souza, F. H. N., De Almeida, L. R., Batista, F. S. C. L., De, S., \& Rios, M. (2011). Uv-visible spectroscopy study of oxidative degradation of sunflower biodiesel. Energy Sci Technol, 2, 56-61.

Tanoitu, K., Elamrani, A., Serghini-Caid, H., \& Tahani, N. (2011). Quality of olive oils produced in east of morocco. Electron Journal of Environmental, Agricultural and Food Chemistry (EJEAFCHe), 10(7), 2439-2540.

Vacca, V., Del Caro, A., Poiana, M., \& Piga, A. (2006). Effect of storage period and exposure conditions on the quality of bosana extra-virgin olive oil. Journal of Food Quality, 29(2), 139-150. doi:10.1111/j.17454557.2006.00062.x

Vekiari, S. A., Papadopoullou, P., \& Kiritsakis, A. (2007). Effects of processing methods and commercial storage conditions on the extra virgin olive oil quality indexes. Grasas Y Aceites, 58(3), 237-242. 